\title{
Presença do vírus da síndrome da mancha branca em crustáceos decápodes silvestres em lagoas costeiras no Sul do Brasil
}

\author{
[Presence of the white spot syndrome virus (WSSV) in wild decapods crustaceans in coastal \\ lagoons in southern Brazil] \\ S.W. Costa ${ }^{1}$, A.P.M. Fraga ${ }^{2}$, A.S. Zamparetti ${ }^{1}$, M.R.F. Marques ${ }^{2}$, E.R. Andreatta ${ }^{2}$ \\ ${ }^{1}$ Empresa de Pesquisa Agropecuária e Extensão Rural de Santa Catarina - EPAGRI, SC \\ ${ }^{2}$ Universidade Federal de Santa Catarina - UFSC - Florianópolis, SC
}

\begin{abstract}
RESUMO
A presença do vírus da síndrome da mancha branca (em inglês WSSV) nas principais espécies de camarões, siris e caranguejos de cinco lagoas que recebem o efluente de fazendas afetadas pela enfermidade foi detectada por nested PCR, e inclusões virais nos camarões por histologia. Pela nested PCR encontrou-se a presença de WSSV em 13 de 16 (81,2\%) amostras de camarões da espécie Farfantepenaeus paulensis, em 13 de 14 (92,8\%) de Litopenaeus schmitti, em uma de duas de Farfantepenaeus brasiliensis (50\%), em 13 de 15 (86,6\%) de siri da espécie Callinectes danae e em 11 de $12(91,6 \%)$ de Callinectes sapidus, e não foi detectada no caranguejo Chasmagnathus granulata em 10 amostras. Inclusões características de WSSV foram observadas em três amostras histológicas de 50 $(6,0 \%)$ no epitélio gástrico e cuticular e nas brânquias de dois exemplares de $F$. paulensis e um de $L$. schmitti. É o primeiro relato da presença de WSSV em camarões $L$. schmitti e no siri $C$. danae silvestres. As principais espécies de camarões e siris dos ambientes de entorno das fazendas foram contaminadas pelo WSSV, constituindo-se em vetores potenciais do vírus.
\end{abstract}

Palavras-chave: WSSV, vírus, camarão, siri, caranguejo

\begin{abstract}
The presence of white spot syndrome virus (WSSV) in the main species of shrimps, blue crabs, and burrowing crabs of five lagoons where shrimp farm effluents are discharged, was analyzed by nested PCR and the presence of virus inclusions in the shrimps was analyzed through histopathology. The nested PCR analysis indicated the presence of WSSV in 13 of 16 (81.2\%) samples of the shrimp species of Farfantepenaeus paulensis, in 13 of 14 (92.8\%) of Litopenaeus schmitti, in one of two of Farfantepenaeus brasiliensis (50\%), in 13 of 15 (86.6\%) of blue crab species of Callinectes danae and in 11 of 12 (91.6\%) of Callinectes sapidus and none was detected in the 10 samples of the burrowing crab Chasmagnathus granulata. The inclusion characteristics of WSSV were observed in three samples of $50(6.0 \%)$ in the gastric and cuticular epithelium and in the gills of two specimens of F. paulensis and one of L. schmitti. The presence of WSSV in L. schmitti wild shrimp and in the C. danae blue crab is reported for the first time in the present work. The results indicate that the main species of shrimps and blue crabs of the environment surrounding the farms were infected by WSSV, and they may be considered potential vectors of the virus.
\end{abstract}

Keywords: virus, shrimp, blue crab, burrowing crab

\section{INTRODUÇÃO}

O vírus da mancha branca (WSSV) é um patógeno que tem devastado a indústria do

Recebido em 26 de outubro de 2010

Aceito em 10 de janeiro de 2012

E-mail: winckler@epagri.sc.gov.br cultivo de camarões em vários países (Lightner et al., 1998) e atualmente é considerado o mais sério patógeno viral de camarões no mundo (Flegel, 2009). No Brasil, o primeiro registro de WSSV ocorreu em 2005, em cultivos de 
Litopenaeus vannamei do estado de Santa Catarina (Seiffert et al., 2005). A enfermidade provocou a queda de mais de $90 \%$ na produção de camarões do estado, passando de 4.189t no ano de 2004 para 172t no ano de 2009 (Costa, 2010), afetando a maioria das fazendas.

O WSSV tem sido detectado em uma larga gama de crustáceos silvestres, incluindo camarões peneídeos e não peneídeos, caranguejos, lagostas e outros artrópodos, como copépodos e insetos (Lo et al., 1996a,b). A descarga de água dos cultivos de camarões tem sido apontada como responsável pela contaminação da população natural de decápodes e outros organismos suscetíveis (Lo et al., 1996a,b) e pela alta prevalência de WSSV em organismos silvestres (Meng et al., 2009).

A transferência de WSSV de crustáceos silvestres infectados para camarões de cultivos foi observada por meio de testes de coabitação (Kanchanaphum $e_{i}$ al., 1998) e pela inoculação e ingestão de tecidos contaminados (Momoyama, 2003). Algumas espécies de crustáceos abundantes em fazendas de camarões demonstraram menor suscetibilidade ao WSSV. Tais crustáceos foram considerados hospedeiros assintomáticos e importantes vetores nos surtos da enfermidade (Rajendran et al., 1999).

Informações sobre os hospedeiros de WSSV no ambiente natural e sobre os riscos que eles possam trazer são de grande relevância para a prevenção de infecções pelos criadores de camarão (Chakraborty, 2002).

A principal região produtora de camarões de Santa Catarina está localizada no entorno do Complexo Lagunar Sul, composto por cinco lagoas de água salobra, onde existe importante pesca de camarões subadultos e de siri (Governo..., 2002). Outra espécie de crustáceo encontrada em abundância neste ecossistema é o caranguejo "gatanhão" (Chasmagnathus granulata), frequente nas fazendas de camarão (Marques, 2008).

Avaliou-se a presença de WSSV por meio de nested PCR nos estoques naturais das principais espécies de camarões, siris e caranguejos no Complexo Lagunar Sul, em áreas próximas às fazendas afetadas pela enfermidade da mancha branca. Também foi avaliada a presença de inclusões histopatológicas características de WSSV nas espécies de camarões.

\section{MATERIAL E MÉTODOS}

A área de estudo está inserida na região do Complexo Lagunar Sul de Santa Catarina, abrangendo os municípios de Laguna, Imaruí e Jaguaruna, onde estão instaladas 92 das 106 fazendas de cultivo de camarões do estado, com área de viveiros de 1.207ha. Foram selecionados cinco pontos de amostragem, localizados nas cinco lagoas de água salobra onde são liberados os efluentes dos cultivos, sendo: ponto 1 - Lagoa de Imaruí; ponto 2 - Lagoa do Ribeirão; ponto 3 - Lagoa de Santo Antônio; ponto 4 - Lagoa de Santa Marta e ponto 5 - Lagoa do Camacho (Fig. 1).

As coletas ocorreram no período de maio/junho 2008, após a safra de camarões - dezembro 2007 a março 2008. Em cada lagoa, foram coletados exemplares das espécies de camarões nativos Farfantepenaeus paulsensis (Perez Farfante, 1967), Farfantepenaeus brasiliensis (Latreille, 1817) e Litopenaeus schmitti (Burkenroad, 1936), das espécies de siri Calinectes danae (Smitt, 1869) e Calinectes sapidus (Rathbun, 1896) e do caranguejo Chasmagnathus granulata (Dana, 1851). As espécies de siri e caranguejo foram identificadas pelas características descritas por Mello (1996), e as espécies de camarões pelas características descritas por Pérez-Farfante (1969).

Os camarões foram coletados por meio de tarrafas, e os caranguejos e siris por armadilhas tipo covos. Para cada ponto, foram obtidas amostras de pleópodos dos camarões e de brânquias e patas de siris e caranguejos, para análise de PCR, as quais foram fixadas em etanol $95 \%$, na proporção de 1:10, e colocadas em frascos de vidro. Para análise histológica, foram capturados camarões vivos de tamanho variado, nos quais foi injetada solução de Davidson (Lightner, 1996). Em seguida, foram colocados em frasco com solução de Davidson, onde permaneceram por 24 horas e, após esse período, foram passados para uma solução de etanol $70 \%$, substituído por outro etanol $70 \%$ após 24 horas. 


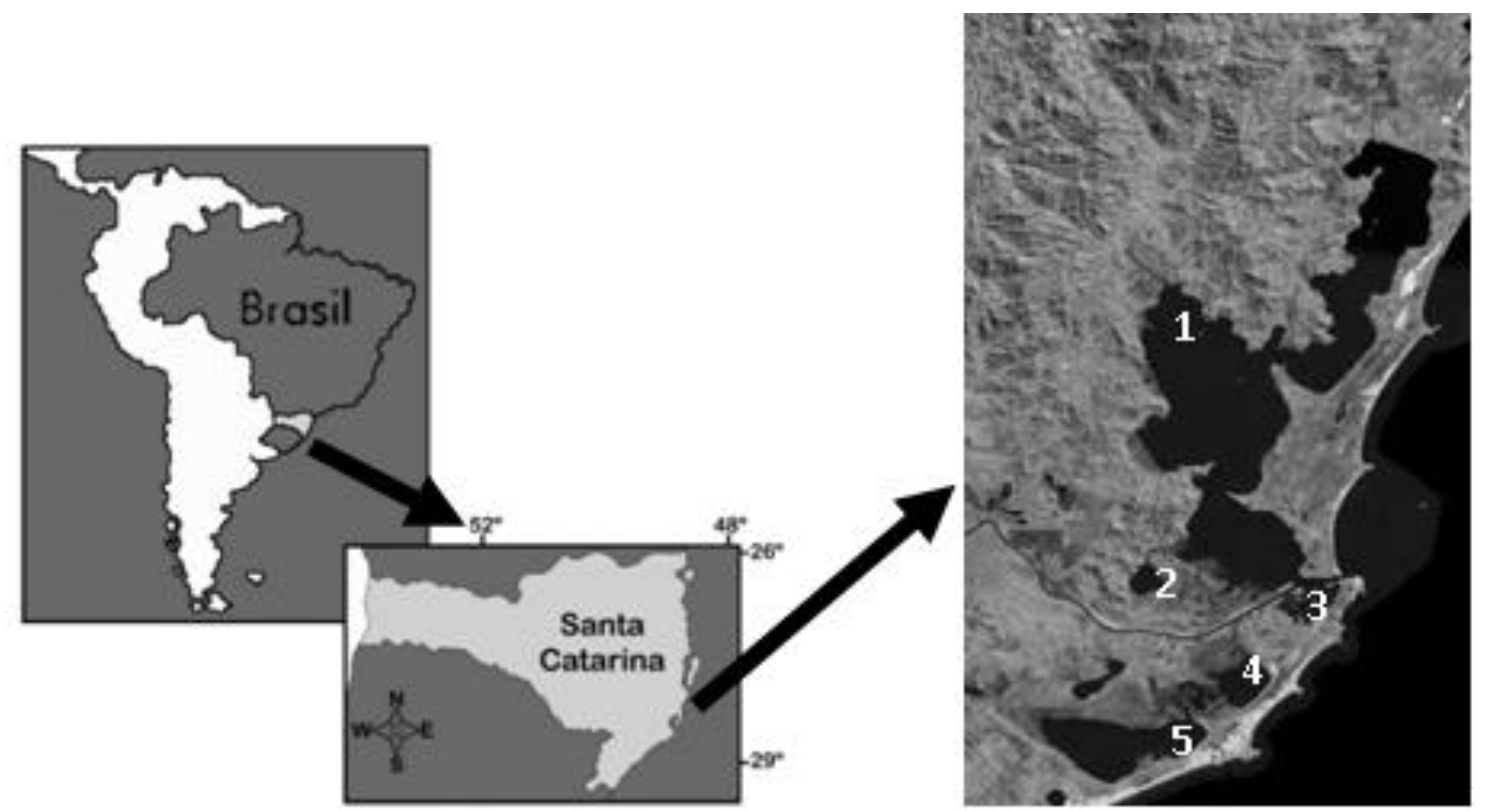

Figura 1. Localização dos pontos de amostragem no Complexo Lagunar Sul de Santa Catarina. 1 - Lagoa de Imaruí; 2 - Lagoa do Ribeirão; 3 - Lagoa de Santo Antônio; 4 - Lagoa de Santa Marta; 5 - Lagoa do Camacho.

Os dados relativos às fazendas afetadas pela mancha branca no período amostral, assim como o local de liberação dos efluentes nas lagoas, as áreas em operação e quantidade de pós-larvas povoadas, foram obtidos junto aos órgãos responsáveis pela extensão e defesa sanitária do estado, aos laboratórios fornecedores de póslarvas e diretamente com os produtores.

Foram preparadas lâminas histológicas de acordo com procedimento descrito por Lightner (1996), em que as amostras fixadas em Davidson foram desidratadas, incluídas em parafina e seccionadas em micrótomo (EP-31-20091, EasyPath) na espessura de $3-5 \mu \mathrm{m}$, coletadas em lâminas e posteriormente coradas em hematoxilina e eosina (HE). As lâminas foram fotografadas (dsc-w 120, Sony) e examinadas em microscópio óptico (Biocular, Bioval) para observação da presença de núcleos hipertróficos com inclusões centrais basófilas cercadas por cromatina marginal em tecidos de origem ectodérmica e mesodérmica (Wongteerasupaya et al., 1995). Os tecidos mais utilizados para observação do WSSV foram o subcuticular do estômago e do cefalotórax e as brânquias.

A extração de DNA genômico foi realizada a partir de amostras compostas por um pool de tecidos - brânquias, pleópodos ou patas - de cinco animais, utilizando-se protocolo descrito por Souza (2008). A integridade das amostras foi avaliada pelo seu perfil eletroforético em gel de agarose 1\%. A concentração de DNA foi determinada por meio da razão da absorbância em 260/280nm, por espectrofotometria.

A detecção do vírus da mancha branca foi realizada por meio da amplificação de um fragmento do genoma viral pela reação em cadeia da polimerase (PCR) em dois passos, a nested PCR, utilizando-se dois pares de iniciadores, WS146F1/WS146R1 (externos) e WS146F2/WS146R2 (internos), descritos por Lo et al. (1996a) e recomendados pela OIE. Na primeira etapa, o tamanho do fragmento esperado é de $1447 \mathrm{pb}$, e na segunda etapa de $941 \mathrm{pb}$. Como controle positivo, foi utilizada uma amostra de DNA extraída de pleópodo de $L$. vannamei, cujo resultado foi positivo para a presença de uma sequência gênomica do WSSV, e como controle negativo, foi utilizada uma amostra sem DNA molde. A análise dos produtos de PCR foi realizada por meio de eletroforese em gel de agarose $2 \%$, e o resultado foi fotodocumentado em câmera digital. 


\section{RESULTADOS}

A análise dos produtos da nested PCR por eletroforese em gel de agarose revelou a presença de uma única banda equivalente ao tamanho esperado de $941 \mathrm{pb}$, correspondente à amplificação de um fragmento específico do genoma de WSSV, utilizando-se os indicadores descritos. A presença deste fragmento foi observada em 59 das 118 amostras analisadas
$(50 \%)$. Os resultados positivos para o WSSV obtidos em patas de siri $(8 / 27)$ foram inferiores aos encontrados nas brânquias deste organismo (24/27), optando-se por utilizar somente os resultados das análises nas brânquias no presente trabalho.

$\mathrm{Na}$ Tab. 1, encontram-se os resultados de detecção de WSSV por nested PCR por espécie e local de coleta.

Tabela 1. Resultados de PCR (nested) positiva para WSSV, pelo número total de amostras (pools), por espécie em cada lagoa. WT é o peso total médio, em gramas, LT o comprimento total médio, em centímetros, e $n$ o número de organismos coletados

\begin{tabular}{|c|c|c|c|c|}
\hline Lagoa & Espécies & PCR & $\begin{array}{c}\text { Biometria } \\
\mathrm{WT}(\mathrm{g})-\mathrm{LT}(\mathrm{cm})\end{array}$ & $\mathrm{n}$ \\
\hline \multirow[t]{6}{*}{ Imaruí } & Farfantepenaeus paulensis & $0 / 3$ & $\mathrm{WT}-4,9$ & 54 \\
\hline & Litopenaeus schimitti & $2 / 3$ & WT $-7,82$ & 100 \\
\hline & Farfantepenaeus brasiliensis & - & - & - \\
\hline & Calinectes danae & $1 / 3$ & LT $-10,82$ & 50 \\
\hline & Calinectes sapidus & $3 / 3$ & $\mathrm{LT}-12,28$ & 60 \\
\hline & Chasmagnatus granulata & $0 / 2$ & WT $-12,30$ & 80 \\
\hline Santo & F.paulensis & $4 / 4$ & WT $-4,46$ & 100 \\
\hline \multirow[t]{5}{*}{ Antônio } & L. schimitti & $5 / 5$ & $\mathrm{WT}-6,2$ & 100 \\
\hline & F. brasiliensis & - & - & - \\
\hline & C. danae & $3 / 3$ & $\mathrm{LT}-7,6$ & 167 \\
\hline & C. sapidus & $3 / 3$ & $\mathrm{LT}-8,28$ & 50 \\
\hline & C. granulata & $0 / 2$ & WT $-10,20$ & 63 \\
\hline \multirow[t]{6}{*}{ Santa Marta } & F.paulensis & $3 / 3$ & WT $-6,58$ & 100 \\
\hline & L. schimitti & $3 / 3$ & WT $-3,72$ & 100 \\
\hline & F. brasiliensis & $1 / 2$ & WT $-3,78$ & 8 \\
\hline & C. danae & $3 / 3$ & $\mathrm{LT}-7,9$ & 100 \\
\hline & C. sapidus & $3 / 3$ & $\mathrm{LT}-9,12$ & 100 \\
\hline & C. granulata & $0 / 2$ & WT $-11,30$ & 110 \\
\hline \multirow[t]{6}{*}{ Camacho } & F. paulensis & $3 / 3$ & $\mathrm{WT}-7,2$ & 150 \\
\hline & L. schimitti & - & - & - \\
\hline & F. brasiliensis & - & - & - \\
\hline & C. danae & $3 / 3$ & $\mathrm{LT}-8,82$ & 50 \\
\hline & C. sapidus & $2 / 3$ & $\mathrm{LT}-11,84$ & 75 \\
\hline & C. granulata & $0 / 2$ & WT $-10,5$ & 100 \\
\hline \multirow[t]{6}{*}{ Ribeirão } & F.paulensis & $3 / 3$ & WT $-6,4$ & 100 \\
\hline & L. schimitti & $3 / 3$ & $\mathrm{WT}-4,5$ & 100 \\
\hline & F. brasiliensis & - & - & - \\
\hline & C. danae & $3 / 3$ & $\mathrm{LT}-7,32$ & 50 \\
\hline & C. sapidus & - & - & - \\
\hline & C. granulata & $0 / 2$ & WT $-12,3$ & 45 \\
\hline
\end{tabular}

A presença de WSSV foi detectada em 13 de 16 $(81,2 \%)$ amostras de $F$. paulensis, em 13 de 14 $(92,8 \%)$ de L. schmitti, em uma de duas de $F$. brasiliensis $(50 \%)$, em 13 de15 $(86,6 \%)$ de $C$. danae, em 11 de $12(91,6 \%)$ de $C$. sapidus, e não foi detectada em $C$. granulata em 10 amostras. 
$\mathrm{Na}$ análise histológica, foram observadas inclusões correspondentes ao WSSV no epitélio gástrico, no epitélio cuticular e nas brânquias em três das 50 amostras (6,0\%) analisadas (Fig. 2), todas provenientes da Lagoa de Imaruí, em dois exemplares de $F$. paulensis e um de $L$. schmitti.

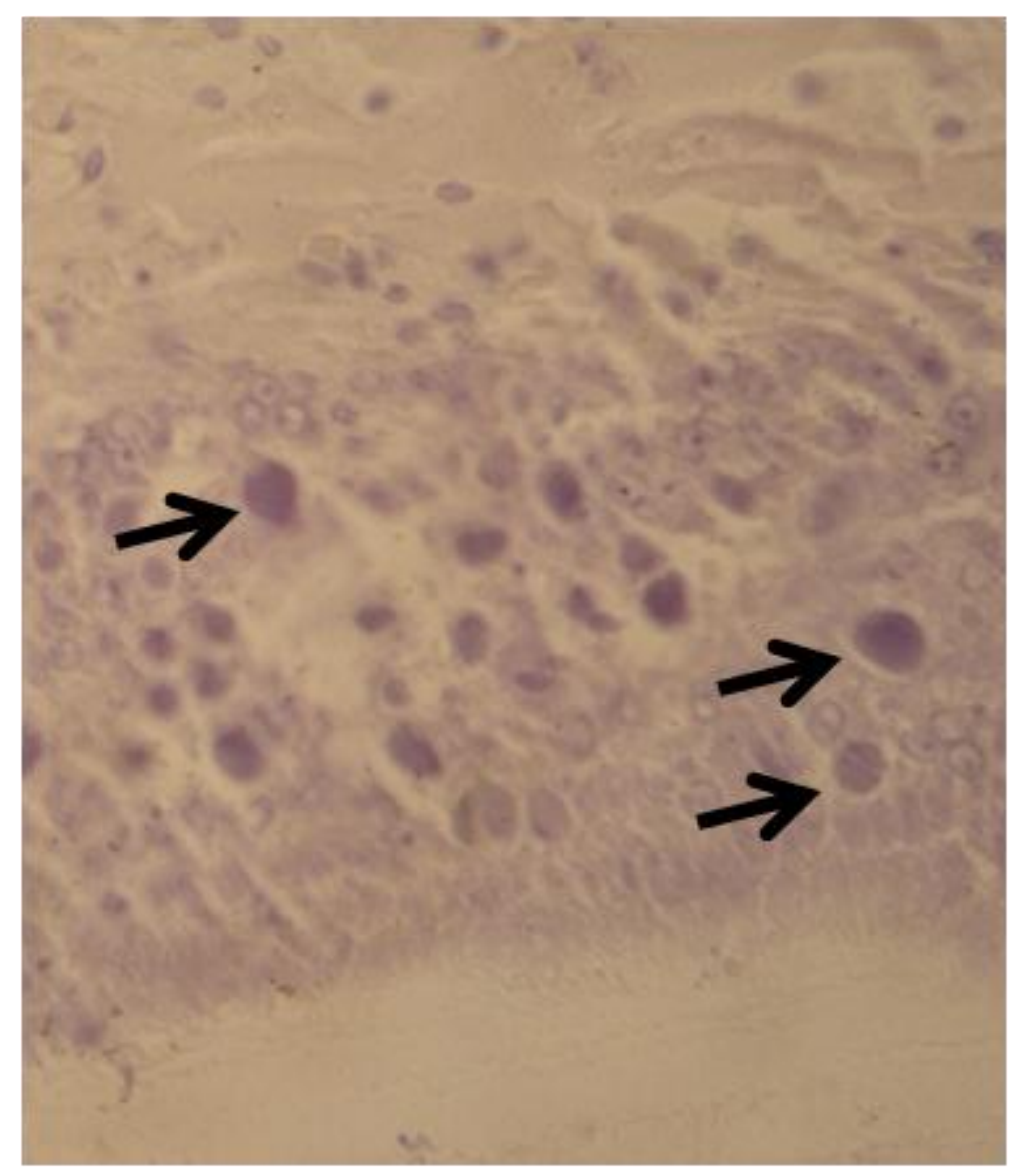

Figura 2. Lesões histológicas características da síndrome do vírus da mancha branca em células do epitélio cuticular de Farfantepenaeus paulensis de amostra da Lagoa de Imaruí. Aumento de 100 X mostrando inclusões centrais em núcleos hipertróficos.

No período anterior à coleta, 15 fazendas realizaram cultivo no entorno das lagoas, das quais 14 apresentaram mortalidades pela mancha branca, com um total de 14.905 milhões de pós larvas povoadas, em uma área de 172ha (Tab. 2).

Tabela 2. Área de viveiros (ha), quantidade de pós-larvas (plsx $10^{3}$ ) e número de fazendas (n) com surtos de vírus da mancha branca por lagoa, na safra anterior à coleta

\begin{tabular}{rlccc}
\multirow{2}{*}{ Safra } & Lagoa & $\begin{array}{c}\text { Área viv. } \\
\text { (ha) }\end{array}$ & Pls. $10^{3}$ & $\mathrm{n}$ \\
\hline \multirow{4}{*}{ Dez-mar/08 } & Ribeirão & 35,2 & 4.340 & 1 \\
& Camacho & 0 & 0 & 0 \\
& Santo Antonio & 70,4 & 6.495 & 6 \\
& Imaruí & 66,56 & 4.070 & 7 \\
& Santa Marta & 0 & 0 & 0 \\
\hline Total & & 172,13 & 14.905 & 14 \\
\hline
\end{tabular}




\section{DISCUSSÃO}

A presença do WSSV foi verificada em três espécies de camarões peneídeos - L. schmitti, $F$. paulensis e F. brasiliensis - e em duas espécies de siri azul silvestres $-C$. danae e $C$. sapidus em lagoas que receberam efluentes de fazendas de camarões que tiveram surtos da enfermidade da mancha branca a partir do ano de 2005.

O diagnóstico de WSSV por nested PCR na espécie C. granulata de amostras da Lagoa de Imaruí coletadas no ano de 2006 foi relatado por Marques (2008). Amostras positivas de WSSV por nested PCR em $F$. paulensis foram encontradas no Complexo Lagunar Sul, no ano de 2008, e em $F$. paulesnis e F. brasiliensis de águas oceânicas, da costa de Santa Catarina e do Rio Grande do Sul, nos anos de 2007 e 2009 (Cavalli, 2009).

A presença de WSSV na espécie $C$. sapidus foi observada em exemplares de canais de fazendas de cultivo de camarão no México (López-Félix, 2002) e em $27,2 \%$ de amostras coletadas na costa de Nova Iorque, Nova Jersey e Texas (Chang et al., 2001). Não foram encontrados relatos anteriores de diagnóstico de WSSV para o camarão L. schmitti e para o siri C. danae capturados na natureza.

Percentuais elevados de WSSV em crustáceos silvestres semelhantes ao observado no presente trabalho foram relatados em estudos anteriores em regiões onde ocorreram surtos da enfermidade. Lo et al. (1996b) detectaram o WSSV em $83,3 \%$ das amostras de camarões $P$. monodon, em $65 \%$ de $P$. japonicus e em $6,2 \%$ de $P$. semisulcatus e em $45,5 \%$ das amostras do caranguejo Hellyce tridens na costa de Taiwan. Meng et al. (2009) encontraram prevalência média de WSSV de 96,4\% em larvas e de $95 \%$ em adultos do caranguejo azul Portunus tritubeculatus silvestre na costa do Mar Amarelo, na China.

A detecção de WSSV nos organismos silvestres foi semelhante entre as lagoas, apesar da não ocorrência de surtos no período anterior à coleta nas lagoas do Camacho e Santa Marta, podendo ser uma decorrência da contaminação dos organismos em anos anteriores e pelo fato de as lagoas estarem conectadas.
A baixa presença de inclusões histopatológicas características de WSSV verificadas nos camarões silvestres no presente trabalho é semelhante ao observado em outros estudos. Mijangos-Alquisires et al. (2006) encontraram apenas um camarão com sinais histopatológicos entre 11 camarões $L$. vannamei silvestres positivos por PCR. Chapman et al. (2004) relataram a presença de sinais histopatológicos em apenas um exemplar entre 28 de Penaeus setiferus selvagens positivos por PCR.

A ausência de inclusões histopatológicas em camarões positivos por nested PCR foi relacionada à baixa porcentagem de infecção nestes organismos (Mohan et al., 2002).

O fato de infecções graves raramente serem vistas na natureza, em camarões e caranguejos, poderia ser decorrente da possível vulnerabilidade dos organismos doentes à predação e à rápida progressão da doença, fazendo com que somente os fracamente infectados sobrevivam (Chapman et al., 2004). Entretanto, em regiões onde foram encontradas infecções por WSSV em populações de crustáceos silvestres, poucos indícios do desenvolvimento da doença foram encontrados (Hill, 2000), além da não ocorrência de diminuição na taxa de captura dessas espécies (Flegel, 2009).

Existem evidências de que as doenças que são de pouca ou de nenhuma importância em populações selvagens em seus hábitats naturais somente se tornem epidêmicas em condições intensivas de cultivo (Brigs et al., 2004). Lo et al. (1996b) observaram que algumas espécies de caranguejos e pequenos camarões selvagens portadores de WSSV eram assintomáticos em condições naturais e, quando foram transferidos para laboratório, morreram em poucos dias, com sinais clínicos da enfermidade. A transferência do WSSV de crustáceos selvagens infectados para camarões de cultivo foi comprovada por meio de testes de coabitação via água de caranguejos para o camarão Penaeus monodon (Kanchanaphum et al., 1998) e pela inoculação e ingestão de porções de camarões silvestres para o camarão Penaeus japonicus (Momoyama, 2003).

Este estudo sugere a necessidade da aplicação de medidas de controle para evitar o ingresso de espécies de crustáceos silvestres nos cultivos, 
vetores potenciais do WSSV, e para que não ocorra a liberação de efluentes contaminados com o vírus no ambiente natural.

\section{CONCLUSÕES}

As principais espécies de crustáceos decápodes silvestres do Complexo Lagunar Sul foram contaminadas pelo vírus da síndrome da mancha branca a partir do efluente de fazendas de camarões afetadas pela enfermidade.

\section{AGRADECIMENTOS}

À Financiadora de Estudos e Projetos FINEP, pela disponibilidade dos recursos financeiros utilizados na pesquisa. À Empresa Brasileira de Pesquisa Agropecuária EMBRAPA, pelo fornecimento de Bolsa de Doutorado para Sérgio Winckler da Costa.

\section{REFERÊNCIAS}

BRIGGS, M.; FUNGE-SMITH, S.; SUBASINGHE, R. et al. Introductions and movement of Penaeus vannamei and Penaeus stylirostris in Asia and the Pacific. RAP publication 2004/10, FAO. Bangkok, 2004. 92 p.

CAVALLI, L. White spot syndrome em camarões peneídeos nativos e cultivados no estuário da Lagoa dos Patos, Sul do Brasil. 2009. 137f. Tese (Doutorado em Oceanografia Biológica) - Universidade Federal do Rio Grande, Rio Grande.

CHAKRABORTY, A.; OTTA, S.K., JOSEPH, B. et al. Prevalence of white spot syndrome virus in wild crustaceans along the coast of India. Current Sci., v.82, p.1392-1397, 2002.

CHANG, Y.S.; PENG, S.E.; WANG, H.C. et al. Sequencing and Amplified Restriction Fragment Length Polymorphism Analysis of Ribonucleotide Reductase Large Subunit Gene of the White Spot Syndrome Virus in Blue Crab (Callinectes sapidus) from American Coastal Waters. Mar. Biotechnol., v.3, p.163-171, 2001.

CHAPMAN, R.W.; BROWDY, C.L.; SAVIN, S. et al. Sampling and evaluation of white spot syndrome virus in commercially important Atlantic penaeid shrimp stocks. Dis. Aquat. Org., v.59, p.179-185, 2004.
COSTA, S.W. Aquicultura no Estado de Santa Catarina: situação atual e perspectivas. Rev. $A B C C$, v.12, p.49-50, 2010.

FLEGEL, T.W. Review of disease transmission risks from prawn products exported for human consumption. Aquaculture, v.290, 179-189, 2009.

GOVERNO DO ESTADO DE SANTA CATARINA. Plano integrado de recursos hídricos da bacia hidrográfica do Rio Tubarão e complexo lagunar. 2002. 930p. Disponível em: www.aguas.sc.gov.br/sirhsc/biblioteca_visualizar _arquivos.jsp? IdEmpresa=1\&idPasta=116. Acessado em: 05 fev.2010.

HILL, B. National and international impacts of white spot disease of shrimp. Bull. Eur. Ass. Fish Pathol, v.2, p.58-65, 2002.

KANCHANAPHUM, P.; WONGTEERASUPAYA, C.; SITIDILOKRATANA, N. et al. Experimental transmission of White Spot Syndrome Virus (WSSV) from crabs to shrimp Penaeus monodon. Dis. Aquat. Org., v.34, p.1-7, 1998.

LIGHTNER, D.V. Handbook of Pathology and Diagnostic Procedures for Diseases of Penaeid Shrimp. USA: World Aquaculture Society, 1996. $304 \mathrm{p}$

LIGHTNER, D.; HASSON, K.; WHITE, B. et al. Experimental infection of western hemisphere penaeid shrimps with Asian white spot syndrome virus and Asian yellow head virus. J. Aquat. Anim. Health, v.10, p.271-281, 1998.

LO, C.F.; LEI, J.H.; HO, C.H. et al. Detection of baculovirus associated with white spot syndrome (WSBV) in penaeid shrimps using polymerase chain reaction. Dis. Aquat. Org., v.25, p.133141, 1996a.

LO, C.F.; HO, C.H.; PENG, S.E. et al. White spot syndrome baculovirus WSBV.detected in cultured and captured shrimp, crabs and other arthropods. Dis. Aquat. Org., v.27, p.215-225, 1996b.

LÓPEZ-FÉLIX, S.C. Determinación y evaluación por PCR, de la presencia del vírus del síndrome de la mancha blanca (WSSV), en unidades de producción camaronícola del estado de Sinaloa 2002. Dissertación (Maestria) Centro de Investigación em Alimentación y Desarrollo, Mazatlán. 
MARQUES J.S. Contribuição para o monitoramento do vírus da Síndrome da Mancha Branca na carcinicultura de Santa Catarina. 2008, 51f. Dissertação (Mestrado em Aquicultura) - Universidade Federal de Santa Catarina, Florianópolis.

MELLO, G.A.S. Manual de identificação dos Brachyura (caranguejos e siris) do Litoral Brasileiro. Plêiade/FAPESC. 1996, 604 p.

MENG, X.H.; JANG, I.K.; SEO, H.C. et al. White spot syndrome virus quantification in blue crab Portunus trituberculatus hatchery-produced larvae and wild populations by TaqMan real-time PCR, with an emphasis on the relationship between viral infection and crab health. Aquaculture, v.291, p.18-22, 2009.

MIJANGOS-ALQUISIRES, Z.; QUINTEROARREDONDO, N.; CASTRO-LONGORITA, R. et al. White spot syndrome (WSSV) in Litopenaeus vannamei captured from the Gulf of California near of extensive aquaculture activity. Dis. Aquat. Org., v.71, p.87-90, 2006.

MOHAN, C.V.; CORSIN, F.; THAKUR, P.C. et al. Usefulness of dead shrimp specimens in studying the epidemiology of white spot syndrome virus (WSSV) and chronic bacterial infection. Dis. Aquat. Org., v.50, p.1-8, 2002.

MOMOYAMA, K. Detection of White Spot Syndrome Virus from Small Penaeid Shrimp Species Caught in teh Western Seto Inland Sea. Fish Pathol., v.38, p.81-85, 2003.
PEREZ-FARFANTE, I. Western Atlantic shrimps of the genus Penaeus. Fish. Bull., v.67, p.462-591, 1969.

RAJENDRAN, K.V.; VIJAYAN, K.K.; SANTIAGO, T.C. et al. Experimental host range and histopathology of white spot syndrome virus (WSSV) infection in shrimp, prawns, crabs and lobsters from India. J. Fish Dis., v.22, p.183-191, 1999.

SEIFFERT, W.; COSTA, S.W.; MAGGIONI, D.A mancha branca em Santa Catarina. Revista Panorama da Aquicultura, v.15, p.51-53, 2005.

SOUZA, T.M. Detecção do vírus da mancha branca (WSSV) em Litopenaeus vannamei por métodos de diagnóstico moleculares: hibridização in situ e PCR em tempo real. 2008. 46f. Dissertação (Mestrado em Aquicultura) Universidade Federal de Santa Catarina, Florianópolis.

WONGTEERASUPAYA, C.; VICKERS, J.E.; SRIURAIRATANA, S. et al. A non-occluded, systemic baculovirus that occurs in cells of ectodermal and mesodermal origin and causes high mortality in the black tiger prawn Penaeus monodon. Dis. Aquat. Org., v.21, p.69-77, 1995. 